NOTICE: This is the author's version of a work that was accepted for publication in Composites Part A: Applied Science and Manufacturing. Changes resulting from the publishing process, such as peer review, editing, corrections, structural formatting, and other quality control mechanisms may not be reflected in this document. Changes may have been made to this work since it was submitted for publication. A definitive version was subsequently published in Composites Part A: Applied Science and Manufacturing, 42, 10, 2011 DOI 10.1016/j.compositesa.2011.06.015 


\title{
Correlation of mechanical performance and morphological structures of epoxy micro/nanoparticulate composites
}

\author{
Yu Dong a,", Deeptangshu Chaudhary ${ }^{\mathrm{b}}$, Charlie Ploumis ${ }^{\mathrm{a}}$, Kin-Tak Lau ${ }^{\mathrm{c}}$ \\ ${ }^{a}$ Department of Mechanical Engineering, Curtin University of Technology, Perth \\ WA 6845, Australia \\ ${ }^{\mathrm{b}}$ Department of Chemical Engineering, Curtin University of Technology, Perth \\ WA 6845, Australia \\ ${ }^{\mathrm{c}}$ Centre of Excellence in Engineered Fibre Composites (CEEFC), Faculty of \\ Engineering and Surveying, University of Southern Queensland, Toowoomba, QLD \\ 4350,Australia
}

\begin{abstract}
Epoxy composites reinforced with zinc oxide nanoparticles, alumina microparticles and nanoclays at 1, 3, 5 and $8 \mathrm{wt} \%$ were fabricated by combined mechanical stirring and ultrasonication processes. The reinforcement efficiency was determined from the composite flexural and impact properties with the correlation to the morphological structure and interfacial bonding effect via scanning electron microscopy (SEM) and X-ray diffraction (XRD). The results reveal the moderate enhancement of composite modulus up to a maximum $27 \%$ for $8 \mathrm{wt} \%$ alumina inclusions; flexural strengths increase quite marginally or even show a decreasing trend with increasing the particle content by weight. The comparison between a series of mathematical models and experimental data of flexural moduli indicates the applicabilities of Paul model for alumina and zinc oxide reinforcements, and Kerner model and Ishai-Cohen model for nanoclays. The appropriate micro/nanoparticle selection due to different shapes and sizes is critical for the better mechanical performance of their composite materials.
\end{abstract}

Keywords: A. Particle-reinforcement; A. Polymer-matrix composites (PMCs); B. Mechanical properties; B. Microstructures

\footnotetext{
* Corresponding author. Tel.: +61 8 92669055; fax: +61 892662681 .

E-mail address: Y.Dong@curtin.edu.au (Y. Dong).
} 


\section{Introduction}

Polymer particulate reinforced composites have led to the development of innovative products in the automotive, aerospace, electronics and many other industries by combining specific and unique mechanical and thermal properties as well as low specific weight and high resistance to degradation [1]. Epoxy resin is one of typical thermosetting materials with particular interest due to its easy processing and fabrication, simple tooling and excellent adhesive and optically transparent properties in aerostructures. In recent years micro/nanoparticles such as calcium silicate microparticles [1], alumina nanoparticles [1, 2], carbon nanotubes [3, 4], nanosilica [5, 6], nanoclays [7-9], nanotitania [10] as rigid reinforcements within epoxy matrix have also attracted widespread attention. The general manufacturing processes for epoxy particulate reinforced composites consist of mechanical shear mixing $[1,9]$, ultrasound sonication $[4,8]$ and other thermal and chemical methods to reduce the resin viscosity and surface tension $[1,4]$ in order to increase the overall particle dispersability level.

On the other hand, the particle size and shape in relation to the aspect ratio also play a leading role in the mechanical performance of their composite counterparts. When particles reduce their sizes from micro- to nanoscale, a much larger surface-tovolume ratio could be achieved with a higher percentage of particle atomic surfaces interacting with the matrix, known as "surface interaction" [6]. Moreover, particles with either large sizes in agglomeration or high aspect ratios can induce easier crack propagation owing to the stress concentration in particulate reinforced composites [1]. The other distinct advantage of nanocomposites over microcomposites lies in the performance improvement that is often acquired at a relatively low concentration of nanoparticles [10]. The particle contents in the range of 3 to $5 \mathrm{wt} \%$ have been shown 
to give the significant improvement of mechanical properties in most polymer composites reinforced with nanoclays [9] while the best mechanical properties for those by single-walled carbon nanotubes (SWCNT) are reached at even lower content of $0.5 \mathrm{wt} \%$ [4].

The present work attempts to evaluate different types of micro/nanoparticles in varied sizes and shapes to establish a clear understanding on how the morphological structures in terms of particle dispersion and interfacial surface interaction can influence the resulting mechanical properties of particulate reinforced composites.

\section{Experimental setup}

\subsection{Material processing and fabrication}

A low viscosity multi-purpose two part epoxy resin L13 (Viscosity: mixed $0.05 \mathrm{~Pa} \cdot \mathrm{s}$ and mix ratio of 3:1 for epoxy and hardener components) was purchased from Adhesive Engineering Pty, NSW, Australia. Platelet-like PLATYL ${ }^{\mathrm{TM}}$ alumina microparticles ( $300 \mathrm{~nm}$ in thickness) and NanoZ-Plus ${ }^{\mathrm{TM}}$ zinc oxide nanoparticles in spherical shape (average size of $30 \mathrm{~nm}$ ) were kindly donated by ANTARIA Ltd, WA, Australia. Cloisite ${ }^{\circledR}$ 30B nanoclay powders manufactured by Southern Clay Products (SCP), USA were also used in this study.

The epoxy resin was pre-heated using an IKA heating plate up to $50^{\circ} \mathrm{C}$. Then the respective particles were added very slowly into the resin in a $100 \mathrm{ml}$ beaker with the aid of a mechanical stirrer IKA RW20 running at $200 \mathrm{rpm}$. To reduce the particle agglomerates by shear mixing, the mixture was further homogenised at a relatively high stirring speed of $500 \mathrm{rpm}$ for 30 mins. After being sealed in a polyethylene bag, it was transferred and submerged by water in an ultrasonic cleaning unit ELMA Ti-H$5(25 \mathrm{kHz}$ in frequency, $60 \%$ power intensity with a sweep mode) for 15 mins to achieve the finer particle dispersion. The hardener was poured into the mixture after it 
had cooled down to ambient temperature. Hand stirring continued for the hardener homogenisation throughout the whole mixture which was subsequently placed in the vacuum oven at a differential pressure of $-100 \mathrm{kPa}$ to remove the air bubbles. The total material handling time was controlled for about 10 to 15 mins.

The processed mixture underwent solution casting at room temperature into the predesigned strip-like testing mould cavities. Slurry samples were covered by acetate thin plastic films from the top and bottom mould surfaces to minimise trapped air bubbles. The fabricated samples were cured at $24^{\circ} \mathrm{C}$ for $24 \mathrm{hrs}$ in the air-circulating oven prior to demoulding.

\subsection{Testing and characterisation techniques}

Strip-like samples were tested for the measurement of flexural properties (ASTM D790) by using a three-point bending rig mounted on an INSTRON 1196 frame 5500 series universal testing machine at the cross head speed of $1.27 \mathrm{~mm} / \mathrm{min}$. Similar notched samples using a milling machine $\left(22.5^{\circ}\right.$ notching cutter $)$ according to ASTM D6110, were broken by a Zwick 5102 (model D-7900) Charpy impact tester for obtaining the corresponding impact properties. Scanning electron microscopy (SEM) was carried out to characterise the sample fracture surfaces from Zeiss Neon 40EsB Focussed Ion Beam (FIB) attached to an energy dispersive X-ray spectroscopy (EDS) system (INCA x-act EDS detector, Oxford Instruments, UK) for material element analysis at the accelerating voltage of $5 \mathrm{keV}$. The SEM samples were initially sputter coated with a $5 \mathrm{~nm}$ layer of platinum/palladium alloy (80/20 ratio). The clay dispersion level was evaluated using an X-ray diffraction (XRD) analysis. A Brucker D8 ADVANCE diffractometer (Germany) was operated at $40 \mathrm{kV}$ and $40 \mathrm{~mA}$ with $\mathrm{Cu}-\mathrm{k}_{\alpha} \mathrm{X}$-ray beam (wave length $\lambda=0.1541 \mathrm{~nm}$ ). The scanning rate was controlled at $0.4^{\circ} / \mathrm{min}$ with $2 \theta$ diffraction angles from 2 to $10^{\circ}$. 


\section{Mathematical models for particulate reinforced composites}

Very sophisticated theories have been produced to predict the elastic moduli and strengths of polymer particulate reinforced composites, which are elaborately summarised according to the requirements of different material or geometric parameters [11-13]. Six typical mathematical models mentioned below have been used to compare with experimental data for the applicability of those empirical relationships. Corresponding material properties used in this study are listed in Table 1 for the model implementation.

\subsection{Elastic modulus prediction}

\subsubsection{Hashin-Shtrikman model}

When considering the Poisson's contraction of constituent phases, improved bounds for the modulus of two-phase particulate-filled composite materials with the assumption of isotropic and linearly elastic behaviour could be adopted by HashinShtrikman model in the following equations [11, 22, 23]

$$
\boldsymbol{E}_{c}=\frac{9 \boldsymbol{X Y}}{3 \boldsymbol{X}+\boldsymbol{Y}} \quad \text { (Lower bound) }
$$

Where

$$
\boldsymbol{X}=\boldsymbol{K}_{m}+\frac{\phi_{p}}{\left[\frac{1}{\left(\boldsymbol{K}_{p}-\boldsymbol{K}_{m}\right)}\right]+\left[\frac{3 \phi_{m}}{\left(3 \boldsymbol{K}_{m}+4 \boldsymbol{G}_{m}\right)}\right]}
$$

and

$$
\begin{array}{r}
\boldsymbol{Y}=\boldsymbol{G}_{m}+\frac{\phi_{p}}{\left[\frac{1}{\left(\boldsymbol{G}_{p}-\boldsymbol{G}_{m}\right)}\right]+\left[\frac{6\left(\boldsymbol{K}_{m}+2 \boldsymbol{G}_{m}\right) \phi_{m}}{5\left(3 \boldsymbol{K}_{m}+4 \boldsymbol{G}_{m}\right) \boldsymbol{G}_{m}}\right]} \\
\boldsymbol{E}_{c}=\frac{9 \boldsymbol{M N}}{3 \boldsymbol{M}+\boldsymbol{N}} \quad \text { (Upper bound) }
\end{array}
$$

where

$$
\boldsymbol{M}=\boldsymbol{K}_{p}+\frac{\phi_{m}}{\left[\frac{1}{\left(\boldsymbol{K}_{m}-\boldsymbol{K}_{p}\right)}\right]+\left[\frac{3 \phi_{p}}{\left(3 \boldsymbol{K}_{p}+4 \boldsymbol{G}_{p}\right)}\right]}
$$


and

$$
\boldsymbol{N}=\boldsymbol{G}_{\boldsymbol{P}}+\frac{\phi_{m}}{\left[\frac{1}{\left(\boldsymbol{G}_{m}-\boldsymbol{G}_{p}\right)}\right]+\left[\frac{6\left(\boldsymbol{K}_{p}+2 \boldsymbol{G}_{p}\right) \phi_{p}}{5\left(3 \boldsymbol{K}_{p}+4 \boldsymbol{G}_{p}\right) \boldsymbol{G}_{p}}\right]}
$$

$E, K$ and $G$ are the Young's, bulk and shear moduli and the subscripts of $c, m$ and $p$ represent the composites, matrix and particles, respectively. $\phi$ is the volume fraction of constituent in a composite system. Hashin-Shtrikman model is an approximate theory to cover the validity of predicted solution of elastic modulus for particulate reinforced composites between the lower and upper bounds.

\subsubsection{Kerner model}

Kerner model was originally developed to investigate a composite material embedded with spherical particles in a matrix. For composite systems in which the filler is much more rigid than the matrix, Kerner model could be expressed in a simplified form $[11,24,25]$

$$
\frac{\boldsymbol{E}_{c}}{\boldsymbol{E}_{m}}=1+\left(\frac{\phi_{p}}{1-\phi_{p}}\right)\left[\frac{15\left(1-v_{m}\right)}{\left(8-10 v_{m}\right)}\right]
$$

where $v$ is the Poisson's ratio as a material constant.

\subsubsection{Frankle-Acrivos model}

To accommodate the difference in particle geometry as fillers, Frankle-Acrivos model introduced the maximum packing fraction $\phi_{\max }$ in its expression $[12,25,26]$

$$
\frac{\boldsymbol{E}_{c}}{\boldsymbol{E}_{m}}=1+\frac{9}{8}\left[\frac{\left(\frac{\phi_{p}}{\phi_{\max }}\right)^{\frac{1}{3}}}{1-\left(\frac{\phi_{p}}{\phi_{\max }}\right)^{\frac{1}{3}}}\right]
$$

For simplicity, the same $\phi_{\max }=0.637$ [12] was chosen for three fillers used in this study including both alumina and clay in random packing irregular shape as well as zinc oxide in random packing spherical shape. 


\subsubsection{Paul model}

Paul model [11,27] was proposed as an alternative approximate solution based on the assumptions of interfacial adhesion between a cubic filler and a cubic matrix as well as homogeneous stress at a macroscopic level applied to the constituents. Under such a uniform stress on the boundary, the elastic modulus of particulate reinforced composites is derived as

$$
\frac{\boldsymbol{E}_{c}}{\boldsymbol{E}_{m}}=\frac{1+\left(\frac{\boldsymbol{E}_{p}}{\boldsymbol{E}_{m}}-1\right) \phi_{p}^{\frac{2}{3}}}{1+\left(\frac{\boldsymbol{E}_{p}}{\boldsymbol{E}_{m}}-1\right)\left(\phi_{p}^{\frac{2}{3}}-\phi_{p}\right)}
$$

\subsubsection{Ishai-Cohen model}

By applying the uniform normal displacement at the boundary in Paul model, one can obtain Ishai-Cohen model as follows $[11,28]$

$$
\frac{\boldsymbol{E}_{c}}{\boldsymbol{E}_{m}}=1+\frac{\phi_{p}}{\left(\frac{\boldsymbol{E}_{p}}{\boldsymbol{E}_{m}}\right)}-\phi_{p}^{\frac{1}{3}}
$$

\subsection{Strength prediction}

\subsubsection{Nicolais-Narkis model}

Nicolais-Narkis model [29, 30] was initially established to predict the tensile strength of filled polymers which is given by

$$
\frac{\sigma_{c}}{\sigma_{m}}=1-K \phi_{p}^{\frac{2}{3}}
$$

where $\sigma$ is the tensile strength of material and $K$ is a stress concentration factor. Nicolais-Narkis model considers a cubic matrix filled with uniformly dispersed spherical particles in which the fracture is assumed to take place in the minimum cross section of the continuous matrix phase perpendicular to the applied load [11]. 
When $K=1.21$, Eq. (11) gives a lower bound in which no adhesion occurs between spherical fillers and matrix. Under the condition of $K=1.21$, the fraction of $\frac{2}{3}$ means that spherical particles are randomly distributed but the fracture path deviates through the equatorial planes of all spheres [31]. This lower bound has been used to well predict the tensile and flexural strengths of epoxy/glass beads composites [11, 32]. In an extended scope of using Nicolais-Narkis model, the decrease of $K$ due to the change of filler shape has been proven to reduce the stress concentration points on the rigid fillers such as calcium carbonate and talc [30, 33].

\section{Results and discussion}

\subsection{Element analysis for micro/nanoparticles}

The compositions of micro/nanoparticles are clearly illustrated in EDS spectra, Figure 1. Alumina microparticles appear to be composed of predominant aluminum, oxygen and carbon elements. Furthermore, subtle peaks of zirconium are also observed, indicating that zirconium might be introduced (possibly oxidised as zirconia) to be a key alloy element within alumina for the excellent resistance to corrosion and higher toughness $[34,35]$, Fig. 1(a). Zinc oxide nanoparticles show the compositions of zinc, oxygen and carbon while nanoclays possess the elemental carbon, oxygen, aluminum and silicon as a quaternary ammonium salt modified natural montmorillonite (MMT), Figs. 1(b) and (c), respectively.

\subsection{Mechanical properties}

Table 2 summarises the flexural and impact properties of epoxy particulate reinforced composites in this study. The reinforcement effect of all particles within composite materials is manifested especially with $8 \mathrm{wt} \%$ alumina inclusion to achieve the highest improvement of $27 \%$ in flexural modulus, followed by $20 \%$ (5 wt $\%$ zinc oxide) as well as only $12 \%$ (8 wt $\%$ nanoclays) compared to that of neat epoxy. 
Alumina reinforced composites indicate a monotonically enhancing trend in flexural moduli from 3.02 to $3.46 \mathrm{GPa}$ when increasing the particle contents from 1 to $8 \mathrm{wt} \%$. Zinc oxide reinforced composites initially show a similar fashion but gain the moderate modulus drop beyond $5 \mathrm{wt} \%$ zinc oxide. Oppositely, nanoclay reinforced composites present the declined modulus of $2.82 \mathrm{GPa}$ from $5 \mathrm{wt} \%$ clay but regain the increasing modulus of $3.07 \mathrm{GPa}$ at $8 \mathrm{wt} \%$.

The flexural strength of alumina reinforced composites is slightly enhanced by $6 \%$ in relation to only $3 \mathrm{wt} \%$ alumina reinforcements, and a significant decrease by $22 \%$ appears at the high particle content of $8 \mathrm{wt} \%$ as opposed to that of neat epoxy. The inclusions of zinc oxide and clay fail to improve the flexural strengths of respective composites over the entire particle content range. The flexural strengths for zinc oxide reinforced composites are more or less comparable to that of neat epoxy; whereas those for nanoclay reinforced composites have been remarkably reduced with a maximum value of $28 \%$ at $8 \mathrm{wt} \%$ clay content.

Regardless of the types of particles, impact strengths have unanimously decreased, drastically at $1 \mathrm{wt} \%$ particle content (42\% decrease in impact strength). Then they have levelled off, becoming almost constant in the particle content range from 1 to 8 wt\%. It is implied that the inclusions of micro/nanoparticles (especially those undispersed particle agglomerates with high stress concentration effect) to epoxy resin might result in the poor material impact resistance, which will be elaborated in the forthcoming morphological analysis.

\subsection{Morphological evaluation on property-structure relationship}

As illustrated in Fig. 2(a), the SEM micrograph of $3 \mathrm{wt} \%$ alumina reinforced epoxy composites with the highest flexural strength displays good particle dispersion 
in different sizes ranging from less than 1 to $10 \mu \mathrm{m}$ with a majority of small submicroparticles arranged in a random orientation. In contrast, a relatively large portion of particles measured around $10 \mu \mathrm{m}$ appears in the fracture surface of $8 \mathrm{wt} \%$ alumina reinforced composites, Fig. 2(b). In both cases, a common phenomenon has been found that voids or holes due to the particle pull-out are rarely seen, and most particles in both large and small microsizes are well embedded into epoxy resin. Nevertheless, relatively large alumina particles (denoted as particles 4, 5 and 6) tend to initiate more defects of interfacial debonding than smaller counterparts (particles 1 , 2 and 3), Fig. 2(c). As a matter of fact, small gaps on the top and bottom edges of large particles are more likely to be observed along their lateral direction while submicroparticles look more tightly embedded within the matrix with no apparent debonding or gap growth. Large particles due to the clustering effect might impart the stress concentration around their edges, which in turn initiates the cracks through the epoxy matrix. On the contrary, large interfacial areas of sub-microparticles make greater benefits to an effective stress transfer from the matrix to particles. As a result, more stress has to apply for $3 \mathrm{wt} \%$ alumina reinforced composites with strong bonding as compared to $8 \mathrm{wt} \%$ counterparts which could not hold high external load owing to the large crack propagation, resulting in the deterioration of flexural strength (even lower than that of neat epoxy).

On the other hand, the pull-out of localised particle agglomerates in different sizes between 1 and $10 \mu \mathrm{m}$, to a certain extent, becomes quite evident in zinc oxide reinforced epoxy composites irrespective of the particle content, Fig. 3. It might imply the weak interfacial bonding partially contributes to almost level-off tendency of composite flexural strengths relative to that of neat epoxy. Apparently, more submicron or nanosized particles with a uniform dispersion exist at low particle content 
of $3 \mathrm{wt} \%$ without the breakage of spherical particle agglomerates, Fig. 3(a). Nonetheless, the breakage is observed through the large agglomerates for both 5 and 8 wt $\%$, but in a quite different fashion. The agglomerates of 8 wt $\%$ zinc oxide reinforcements tend to be easily broken compared to those of $5 \mathrm{wt} \%$ counterparts. This finding can be explained by the fact that for the $8 \mathrm{wt} \%$ reinforcements the crack propagation path goes through both the epoxy matrix and particle agglomerates along the same plane without changing its directions as seen from circled areas in Fig. 3(c). Conversely, for the $5 \mathrm{wt} \%$ reinforcements the crack was deflected either downwards or upwards with reference to the adjacent matrix planes, Fig. 3(b), which reveals the agglomerates for $5 \mathrm{wt} \%$ zinc oxide reinforcements are much harder to break and have the capability of resisting and deflecting the crack failure. The related breakage mechanisms have been clearly illustrated in Fig. 4 for these two different crack paths. It might also interpret why the better flexural modulus takes place at $5 \mathrm{wt} \%$ zinc oxide followed by worsened one at $8 \mathrm{wt} \%$, in accordance with the previous work [2] that better strain-to-break properties can also coincide with the increase in elastic modulus. Furthermore, zinc oxides as rigid fillers could be very weak and less stiff in bulk structure owing to their soft and porous material characteristics as opposed to alumina, thus giving a clear reflection of lower flexural moduli in Table 2.

With respect to clay reinforced epoxy composites, a significant portion of very large clay agglomerates greater than $10 \mu \mathrm{m}$ are detected within epoxy matrix, as typically depicted in clay contents of 5 and $8 \mathrm{wt} \%$, Figure 5. From the manufacturing process point of view, it could be attributed to the lack of effective dispersion energy to generate the sufficient shearing stress by a simple mechanical stirrer as well as the natural tendency of clay particles to aggregate with the moisture absorption. Furthermore, the use of ultrasonic cleaning unit as the secondary process appears to 
make only minor impact on breaking up the large clay particles since it favours the fine particle dispersion at submicron level. The decrease of the filler aspect ratio due to the clay agglomeration associated with the high stress concentration to initiate the cracks will inevitably lead to the least enhancement of flexural modulus and the maximum decrease of flexural strength accordingly when compared with those of alumina and zinc oxide reinforced composites, Table 1. From the XRD pattern obtained in Fig. 6, Cloisite ${ }^{\circledR}$ 30B nanoclays show a diffraction peak at $2 \theta$ angle of about $4.87^{\circ}$ corresponding to the $\mathrm{d}$-spacing value of $1.81 \mathrm{~nm}$ to the (001) plane. Epoxy/nanoclay composites have all the XRD broadened peaks shifted to higher diffraction angles, suggesting the clay collapsed structure (or "de-intercalation" effect). However, those weak peaks might also signify the prevalent disordered clay agglomerate structures at higher clay content levels beyond $5 \mathrm{wt} \%$ and a certain localised exfoliated structures between 1 and 3 wt $\%$ contents. When nanoclays are randomly dispersed into polymer matrix with a disordered form, the diffraction peaks could be inapparent or sometimes absent irrespective of the dispersion status (i.e. intercalation, exfoliation and clay agglomeration) [9].

As indicated in previous study, the Charpy impact resistance of particulate composites could be adversely affected by (i) the large particle agglomerates as the crack initiators or (ii) high aspect ratio particles with the possible edge effect of large stress concentration $[1,36]$ or (iii) irregular particles with angularities and edges to facilitate the impact failure [1]. Evidently, prepared epoxy/nanoclay composites might fall into the category (i) due to the predominant large agglomerates while epoxy/alumina composites are more likely to be satisfied with both categories (ii) and (iii) with detrimental sharp edges. Quite surprisingly, epoxy/zinc oxide composites have also failed to show any improvement of impact strength despite being such tiny 
nanoparticles in spherical shape (aspect ratio:1), which is totally different from the previous finding [36] that impact properties of filled polymers are mainly enhanced by small particles with low aspect ratio. The frequently observed complete or broken agglomerates of zinc oxide with a size of over $10 \mu \mathrm{m}$ would then interpret this phenomenon if considering the increased stress concentration factors on their edges. As a result, it is more convincing to see the poor impact resistance take place in all particulate composites studied relative to that of neat epoxy.

\subsection{Comparisons with theoretical models}

All the experimental data for the relative flexural moduli of epoxy composites embedded with alumina, zinc oxide and nanoclay fillers are compared with various theoretical models, respectively, Fig. 7. The upper and lower bounds for HashinShtrikman model have widely diverged (despite slight narrow bands for zinc oxide reinforced composites), resulting in the majority of the experimental data falling into these ranges. This finding has indicated that Hashin-Shtrikman model offers quite reasonable analytical solutions for validity in this study. Apparently, Paul model gives the excellent agreement to the experimental data for alumina and zinc oxide reinforced composites, Figs. 7(a) and (b); whereas the data for nanoclay reinforced counterparts coincide well with the Kerner model and Ishai-Cohen model, Fig. 7(c). Paul model is normally applicable to the assumption of a perfect adhesion between the particles and matrix, which favours the alumina reinforced composites with better interfacial bonding effect. However, it was quite controversial for zinc oxide reinforced composites which really lack the good interfacial bonding. The better data fitting of nanoclay reinforced composites with Kerner model suggests that more rigid fillers such as nanoclays are embedded into relatively flexible epoxy matrix when their relative modulus ratio of 65 is taken into account (The Young's modulus of 
epoxy in this study $E_{\text {epoxy }}=2.73 \mathrm{GPa}$ and the Young's modulus of clay $E_{\text {clay }}=178 \mathrm{GPa}$ as listed in Table 1). On the other hand, Frankle-Acrivos model overestimates the results to an intermediate degree as opposed to Paul model though it goes far beyond Hashin-Shtrikman upper bound which is in good accordance with the experimental data up to $1 \mathrm{wt} \%$ zinc oxide inclusions in Fig. 7(b). The overestimation of FrankleAcrivos model might be attributed to the simple relative filler volume fraction $\left(\frac{\phi_{p}}{\phi_{\max }}\right)$ to be used for the prediction of flexural modulus, which only implies the partly dominant effect of particle packing efficiency on the elastic properties since the particle and matrix interfacial interactions, the Young's modulus and Poisson's ratio effects of fillers and matrix are neglected.

The experimental data for the relative flexural strengths are plotted to obtain the best fitting with Nicolais-Narkis model using the least square method [37, 38], Fig. 8. A simple mathematical relationship of stress concentration factor $K$ becomes manifested, which gives $K_{\text {alumina }}<K_{\text {zinc oxide }}<K_{\text {nanoclay }}\left(K_{\text {alumina }}=0.88, K_{\text {zinc oxide }}=1.44\right.$ and $\left.K_{\text {nanoclay }}=2.60\right) . K_{\text {zinc oxide }}$ is very close to that of glass beads $\left(K_{\text {glass beads }}=1.21[11,32]\right)$ by considering the similar spherical shape apart from different nano- and microscaled levels, respectively. The increase of $K$ values inevitably contributes to higher possibility of stress concentration areas amongst the rigid fillers. As a theoretical approach, it further verifies the important experimental investigation in this study that existence of clay agglomerates due to insufficient shearing stress in direct mixing could generate more stress concentration sites that significantly lower the flexural strength of their composite counterparts.

\section{Conclusions}

A simple direct mixing process was implemented successfully via mechanical stirring and ultrasonication. Alumina reinforced epoxy composites offer the best 
improvement of flexural modulus up to $27 \%$ and continuous enhancement as the particle content increases. For zinc oxide reinforced composites, particle pull-out, breakage and aggregation effects are more manifested, resulting in the worsened flexural properties especially between 5-8 wt\% contents. nanoclay reinforced composites possess a significant downward trend in flexural strengths as opposed to neat epoxy, arising from the undispersed large clay agglomerates. The inclusion of all micro/nanoparticles has made a similar sharp decline of impact strengths by $40 \%$ at $1 \mathrm{wt} \%$ particle content, and then impact strengths become totally level-off. Paul model for alumina and zinc oxide reinforcements, Kerner model and Ishai-Cohen model for nanoclay inclusions (especially with prevalent clay agglomerates) were found to be effective in predicting the flexural moduli of three investigated epoxy particulate reinforced composites. Nicolais-Narkis model can also be employed for these composites to interpret the resulting flexural strengths in terms of stress concentration effect. Overall, a judicious choice of particle type and further process optimisation of particle dispersion appears to be very critical for the future implementation of micro/nanoparticulate reinforced composites.

\section{Acknowledgements}

New Staff Academic Development Fund by Curtin Engineering Faculty to Dr. Yu Dong is greatly acknowledged. The authors are also very grateful for the technical supports by Mr. Andreas Viereckl from Department of Mechanical Engineering and Mr. William Richard from Centre for Materials Research (CMR) at Curtin University of Technology. 


\section{References}

[1] Wetzel B, Haupert F, Zhang MQ. Epoxy nanocomposites with high mechanical and tribological performance. Compos Sci Technol 2003; 63(14):2055-67.

[2] Zhao S, Schadler LS, Duncan R, Hillborg H, Auletta T. Mechanisms leading to improved mechanical performance in nanoscale alumina filled epoxy. Compos Sci Technol 2008; 68(14):2965-75.

[3] Kim JA, Seong DG, Kang TJ, Youn JR. Effects of surface modification on rheological and mechanical properties of CNT/epoxy composites. Carbon 2006; 44(10):1898-905.

[4] Liao YH, Marietta-Tondin O, Liang Z, Zhang C. Investigation of the dispersion process of SWNTs/SC-15 epoxy resin nanocomposites. Mater Sci Eng A 2004; 385(1-2): 175-81.

[5] Deng S, Ye L, Friedrich K. Fracture behaviours of epoxy nanocomposites with nano-silica at low and elevated temperatures. J Mater Sci 2007; 42(8):2766-74.

[6] Zhang MQ, Rong MZ, Yu SL, Wetzel B, Friedrich K. Effect of particle surface treatment on the tribological performance of epoxy based nanocomposites. Wear 2002; 253(9-10): 1086-93.

[7] Yasmin A, Luo JJ, Abot JL, Daniel IM. Mechanical and thermal behavior of clay/epoxy nanocomposites. Compos Sci Technol 2006; 66(14):2415-22.

[8] Lam C, Lau K, Cheung H, Ling H. Effect of ultrasound sonication in nanoclay clusters of nanoclay/epoxy composites. Mater Lett 2005; 59(11): 1369-72.

[9] Yasmin A, Abot JL, Daniel IM. Processing of clay/epoxy nanocomposites by shear mixing. Scr Mater 2003; 49(1): 81-6.

[10] Song HJ, Zhang ZZ. Study on the tribological behaviors of the phenolic composite coating filled with modified nano- $\mathrm{TiO}_{2}$. Tribol Int 2008; 41(5):396403.

[11] Ahmed S, Jones FR. A review of particulate reinforcement theories for polymer composites. J Mater Sci 1990; 25(12):4933-42.

[12] Bigg DM. Mechanical properties of particulate filled polymers. Polym Compos $1987 ; 8(2): 115-22$.

[13] Yan W, Lin RJT, Bhattacharyya D. Particulate reinforced rotationally moulded polyethylene composites - Mixing methods and mechanical properties. Compos Sci Technol 2006; 66(13): 2080-8. 
[14] Barrau S, Demont P, Perez E, Peigney A, Laurent C, Lacabanne C. Effect of palmitic acid on the electrical conductivity of carbon nanotubes-epoxy resin composites. Macromolecules 2003; 36(26):9678-80.

[15] Aluminium oxide, Accuratus; 2002. http://www.accuratus.com/alumox.html

[16] Zinc oxide, Wikipedia; 2010. http://en.wikipedia.org/wiki/Zinc_oxide

[17] Cloisite® 30B typical physical properties bulletin, Southern Clay Products, Inc. http://www.scprod.com/product_bulletins/PB\%20Cloisite\%2030B.pdf

[18] Chen CQ, Shi Y, Zhang YS, Zhu J, Yan YJ. Size dependence of Young's modulus in ZnO nanowires. Phys Rev Lett 2006; 96(7): 075505.

[19] Fornes TD, Paul DR. Modeling properties of nylon 6/clay nanocomposites using composite theories. Polymer 2003; 44(17): 4993-5013.

[20] Gao S-L, Mäder E. Characterisation of interphase nanoscale property variations in glass fibre reinforced polypropylene and epoxy resin composites. Compos. Pt. A- Appl Sci Manuf 2002; 33(4): 559-76.

[21] Lipowsky P, Burghard Ž, Jeurgens LPH, Bill J, Aldinger F. Laminates of zinc oxide and poly(amino acid) layers with enhanced mechanical performance. Nanotechnology 2007; 18(34): 345707.

[22] Hashin Z, Shtrikman S. A variational approach to the theory of the elastic behaviour of multiphase materials. J Mech Phys Solid 1963; 11(2):127-40.

[23] Zunjarrao SC, Sriraman R, Singh RP. Effect of processing parameters and clay volume fraction on the mechanical properties of epoxy-clay nanocomposites. $\mathrm{J}$ Mater Sci 2006; 41(8): 2219-28.

[24] Hussain M, Nakahira A, Nishijima S, Niihara K. Effects of coupling agents on the mechanical properties improvement of the $\mathrm{TiO}_{2}$ reinforced epoxy system. Mater Lett 1996; 26(6): 299-303.

[25] Kaully T, Siegmann A, Shacham D. Mechanical behavior of highly filled natural $\mathrm{CaCO}_{3}$ composites: Effect of particle size distribution and interface interactions. Polym Compos 2008; 29(4): 396-408.

[26] Frankel NA, Acrivos A. On the viscosity of a concentrated suspension of solid spheres. Chem Eng Sci 1967; 22(6): 847-53.

[27] Paul B. Prediction of Elastic Constants of Multi-Phase Materials. Thans Amer Inst Mech Eng 1960; 218:36-41. 
[28] Ishai O, Cohen LJ. Elastic properties of filled and porous epoxy composites. Int J Mech Sci 1967; 9(8): 539-46.

[29] Nicolais L, Narkis M. Stress-strain behaviour of styrene-acrylonitrile/glass bead composites in the glassy region. Polym Eng Sci 1971; 11(3): 194-9.

[30] Bramuzzo M, Savadori A, Bacci D. Polypropylene composites: Fracture mechanics analysis of impact strength. Polym Compos 1985; 6(1): 1-8.

[31] Landon G, Lewis G, Boden GF. The influence of particle size on the tensile strength of particulate-filled polymers. J Mater Sci 1977; 12:1605-13.

[32] Nicolais L, Nicodemo L. Strength of particulate composite. Polym Eng Sci 1973; 13(6): 469.

[33] Nicolais L, Nicodemo L. The effect of particles shape on tensile properties of glassy thermoplastic composites. Int J Polym Mater 1974; 3(3): 229-43.

[34] Mévrel R. State of the art on high-temperature corrosion-resistant coatings. Mater Sci Eng A 1989; 120-121(1):13-24.

[35] De Aza AH, Chevalier J, Fantozzi G, Schehl M, Torrecillas R. Crack growth resistance of alumina, zirconia and zirconia toughened alumina ceramics for joint prostheses. Biomaterials 2002; 23(3):937-45.

[36] Riley AM, Paynter CD, McGenity PM, Adam JM. Factors affecting the impact properties of mineral filled polypropylene. Plast Rub Proc Appl 1990: 14(2):8593.

[37] Marquardt, DW. An algorithm for least-squares estimation of nonlinear parameters. J Soc Indust Appl Math 1963; 11(2): 431-41.

[38] Dong Y, Lin RJT, Bhattacharyya D. Determination of critical material parameters for numerical simulation of acrylic sheet forming. J Mater Sci 2005; 40(2): 399-410. 


\section{List of Figures:}

Fig. 1. EDS spectra of micro/nanoparticles embedded in particulate composites: (a) alumina, (b) zinc oxide and (c) nanoclays. SEM micrographs show the circled areas of particle aggregates.

Fig. 2. SEM micrographs of fracture surfaces of alumina reinforced epoxy composites: (a) 3 wt\% alumina, (b) 8 wt\% alumina and (c) stress concentration and debonding zones in a selected rectangular area for $8 \mathrm{wt} \%$ alumina.

Fig. 3. SEM micrographs of fracture surfaces of zinc oxide reinforced epoxy composites with various particle contents: (a) $3 \mathrm{wt} \%$, (b) $5 \mathrm{wt} \%$ and (c) 8 $\mathrm{wt} \%$. Circled areas indicate the breakages take place through the particle agglomerates.

Fig. 4. Breakage mechanisms of large zinc oxide agglomerates in zinc oxide $\quad$ (b) 8 wt $\%$.

Fig. 5. SEM micrographs of fracture surfaces of nanoclay reinforced epoxy composites with two typical particle contents: (a) $5 \mathrm{wt} \%$ and (b) $8 \mathrm{wt} \%$.

Fig. 6 XRD patterns of nanoclays and nanoclay reinforced epoxy composites.

Fig. 7. Relative flexural moduli as a function of particle content in comparison with a series of mathematical models for epoxy particulate composites reinforced with: (a) alumina, (b) zinc oxide and (c) nanoclays.

Fig. 8 Relative flexural strengths as a function of particle content in comparison with Nicolais-Narkis model for epoxy particulate reinforced composites. 

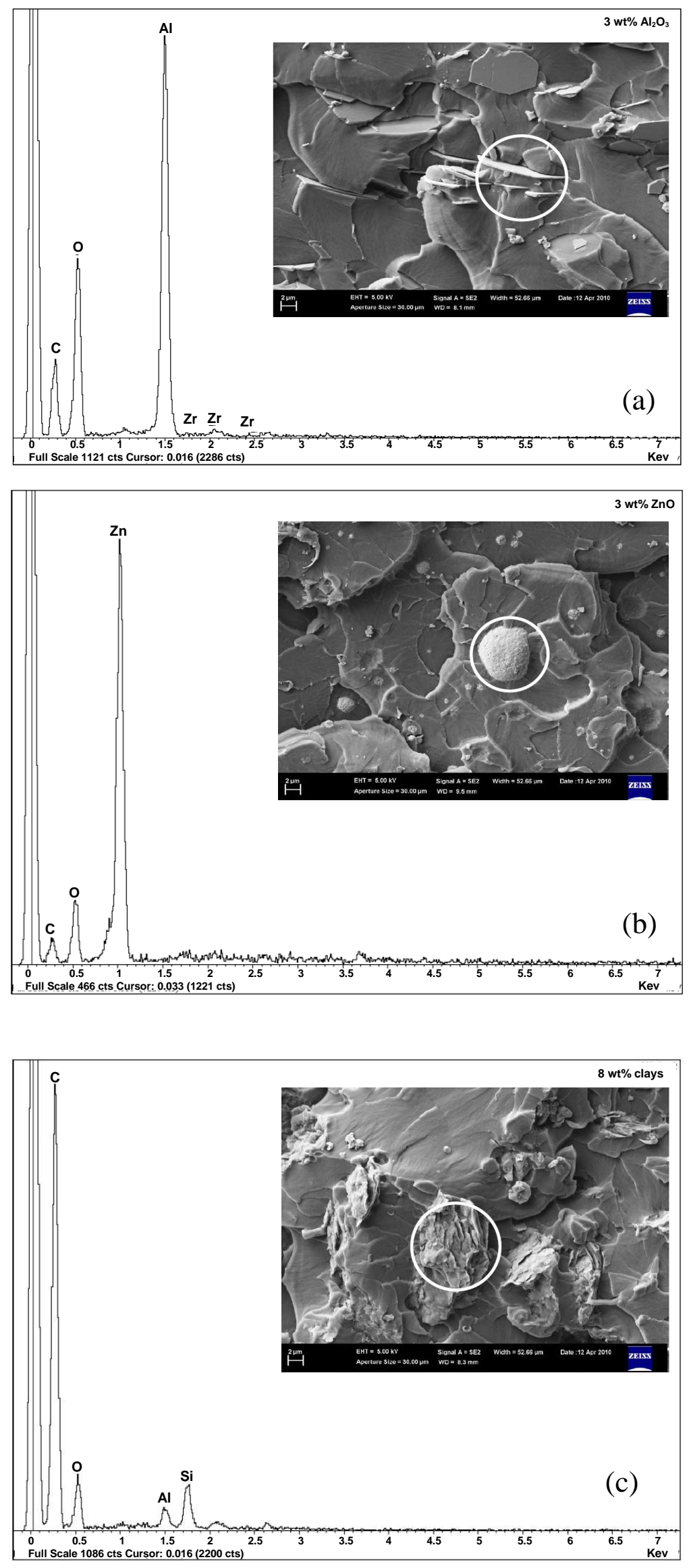

Fig. 1 
(a)
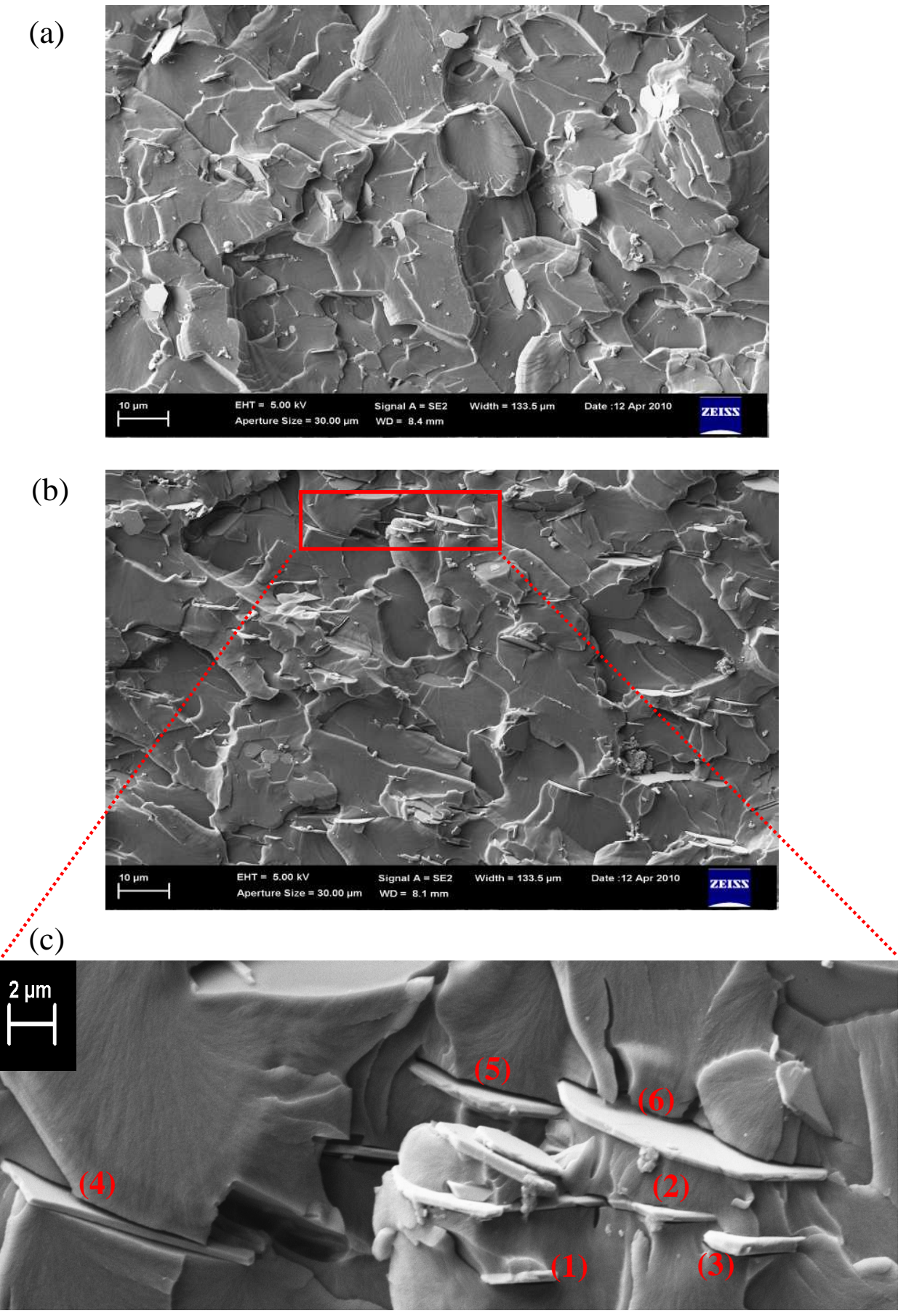

Fig. 2 
(a)

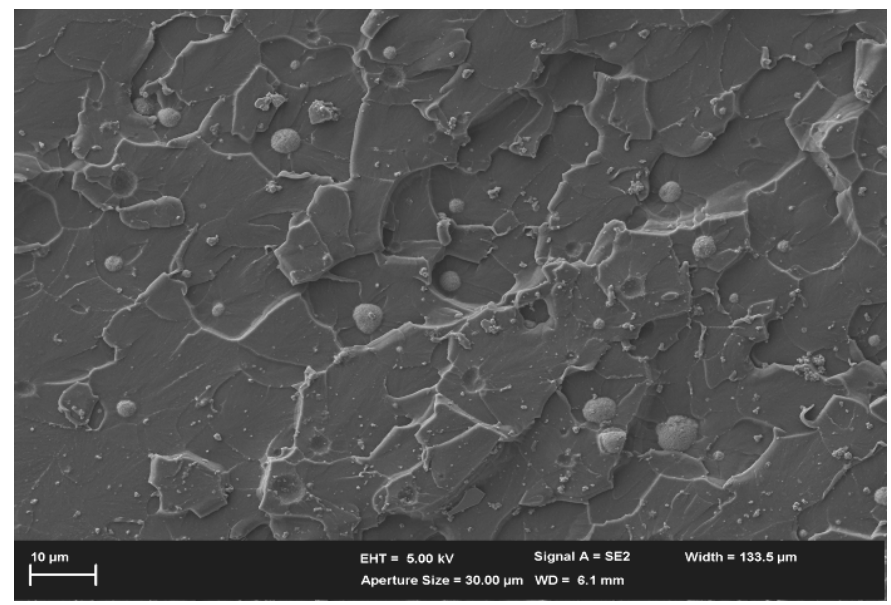

(b)

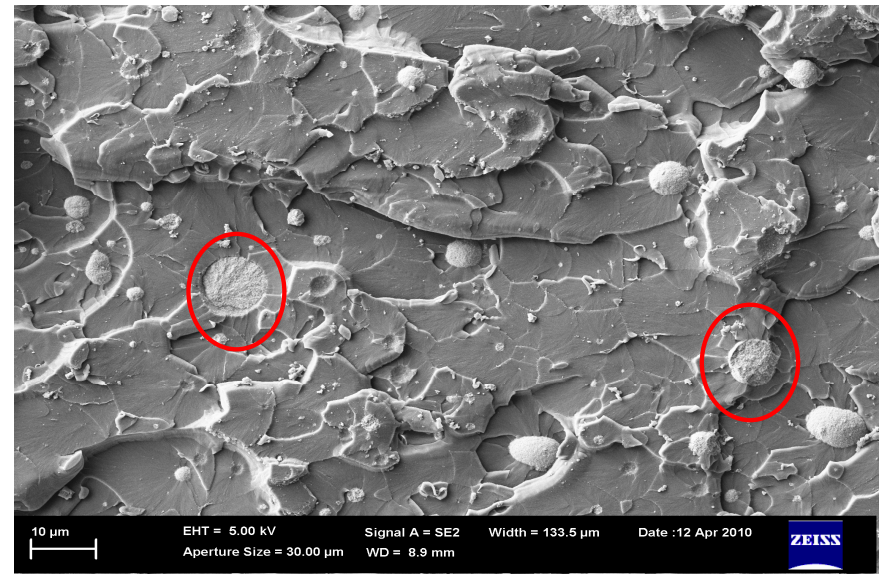

(c)

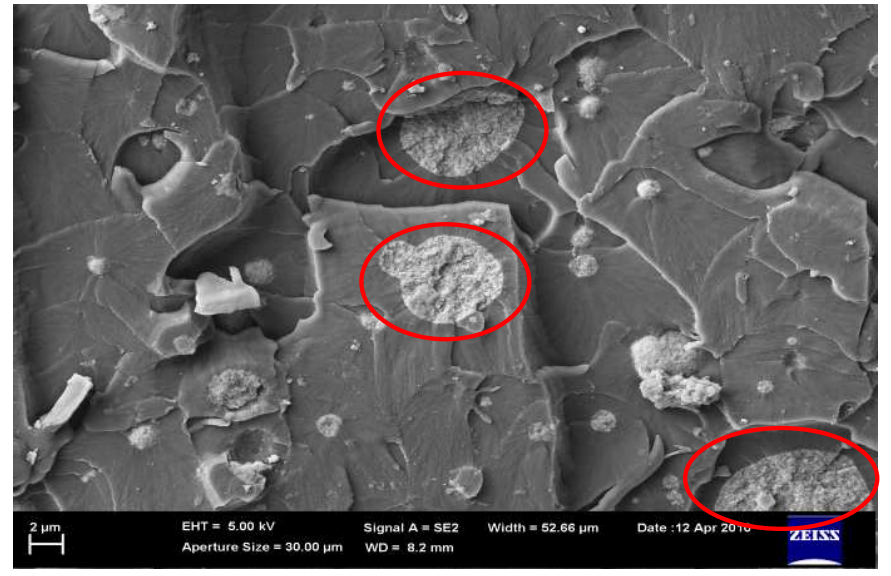

Fig. 3 
a)

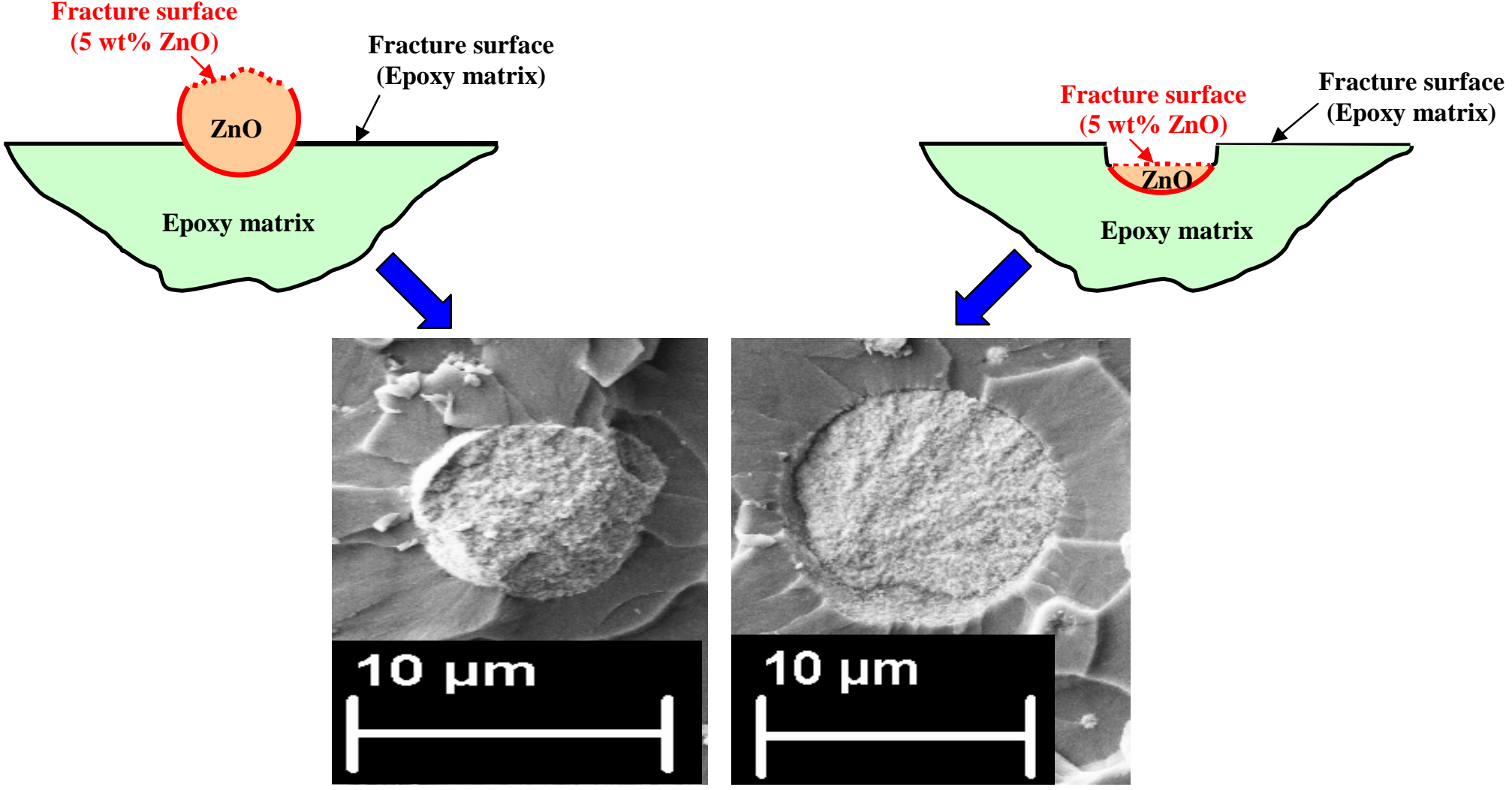

(b)
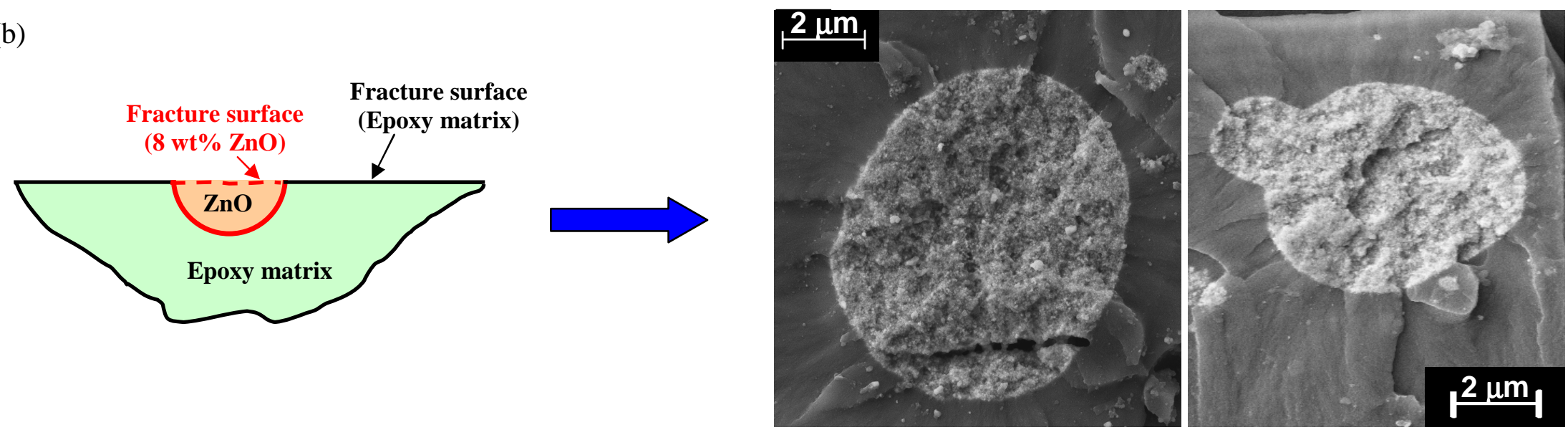

Fig. 4 
(a)

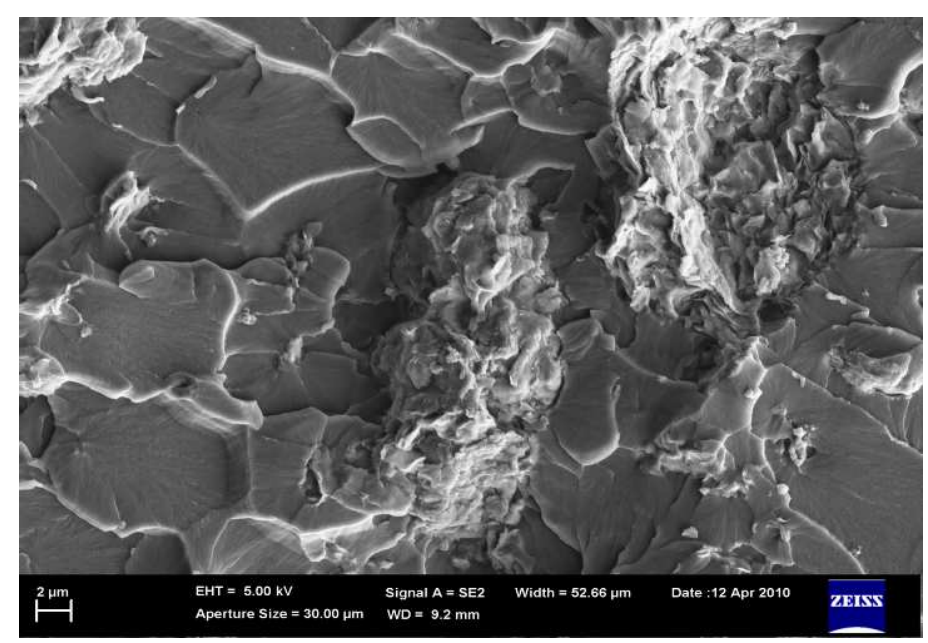

(b)

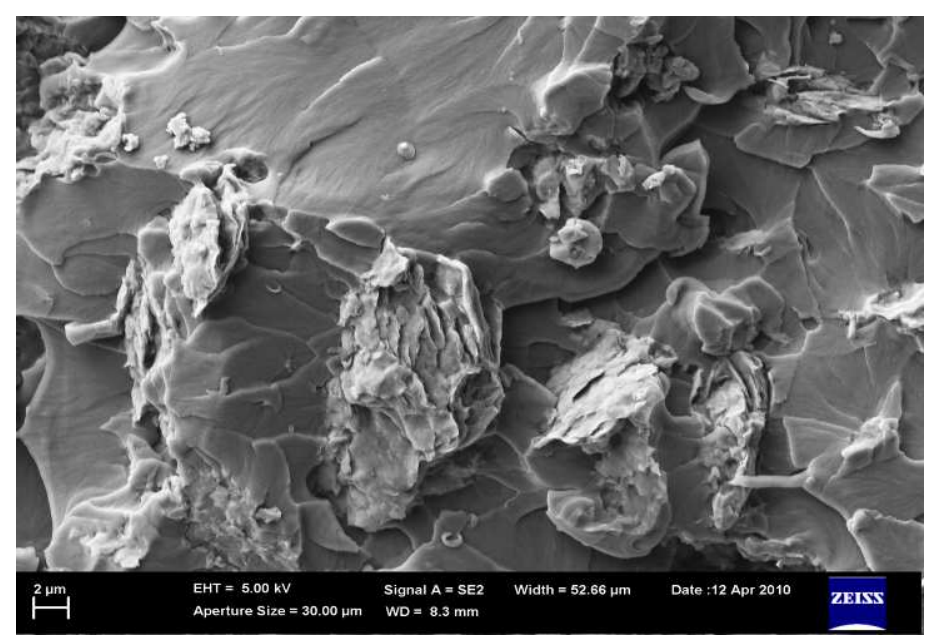

Fig. 5 


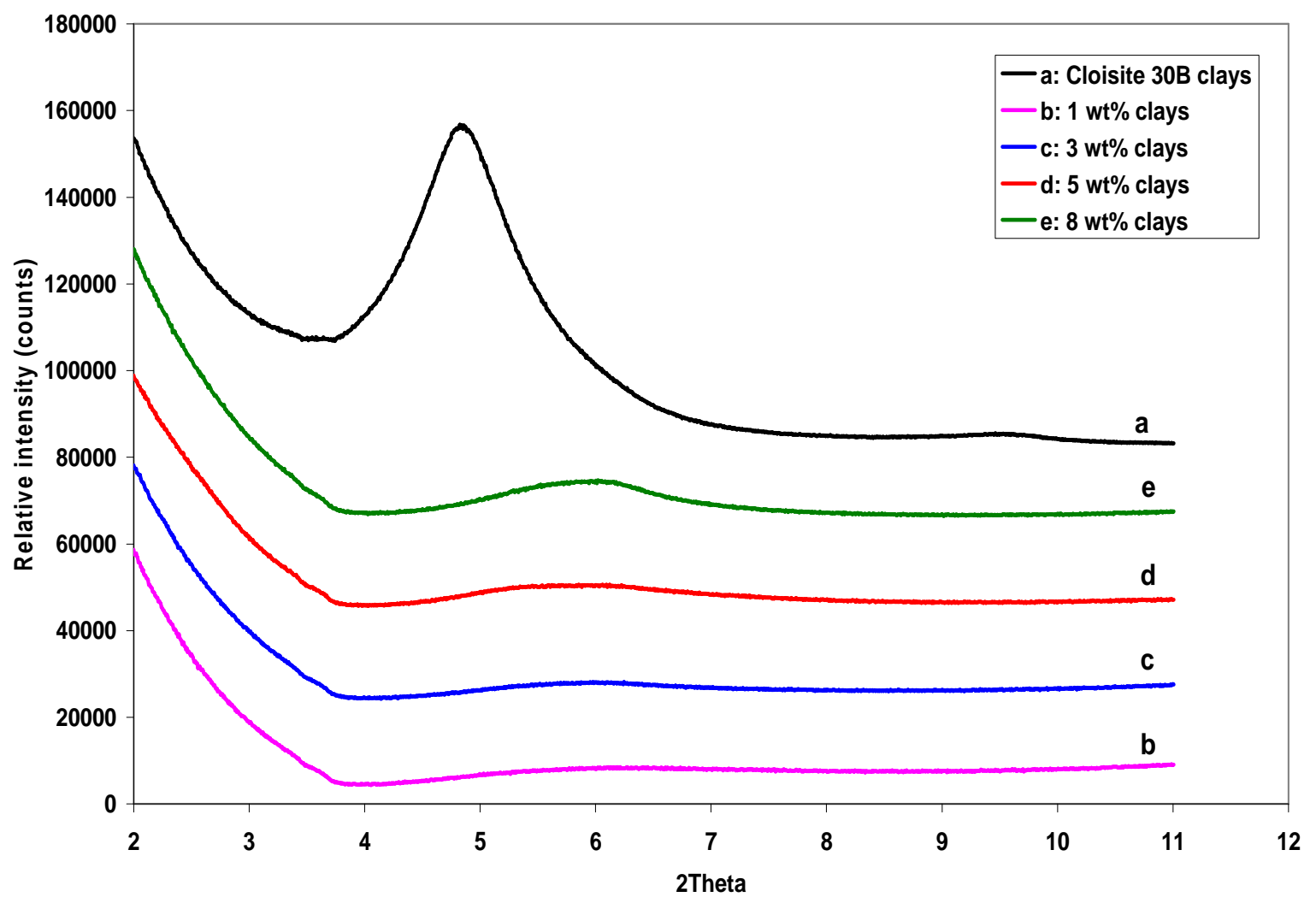

Fig. 6 


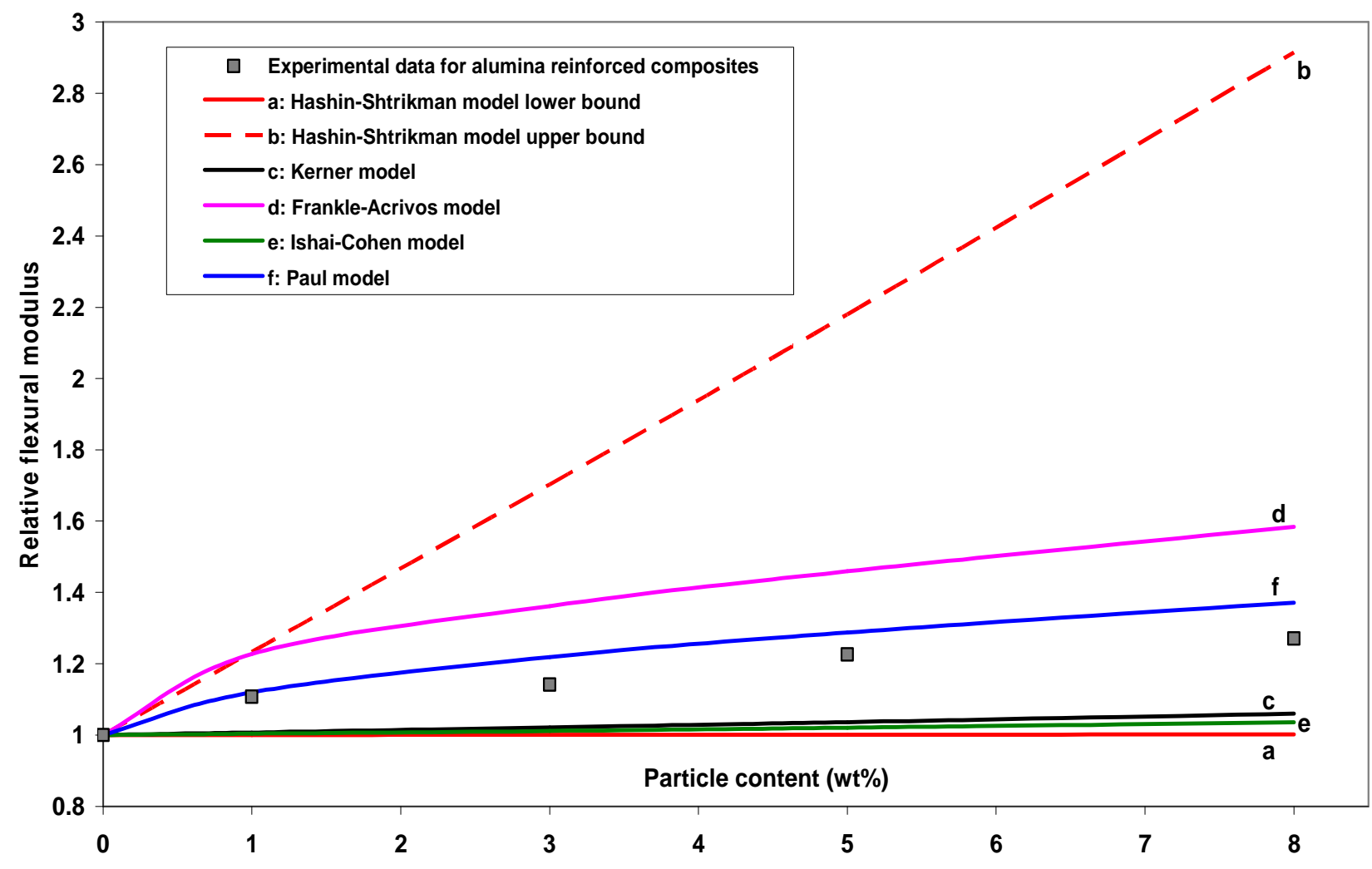

(a)

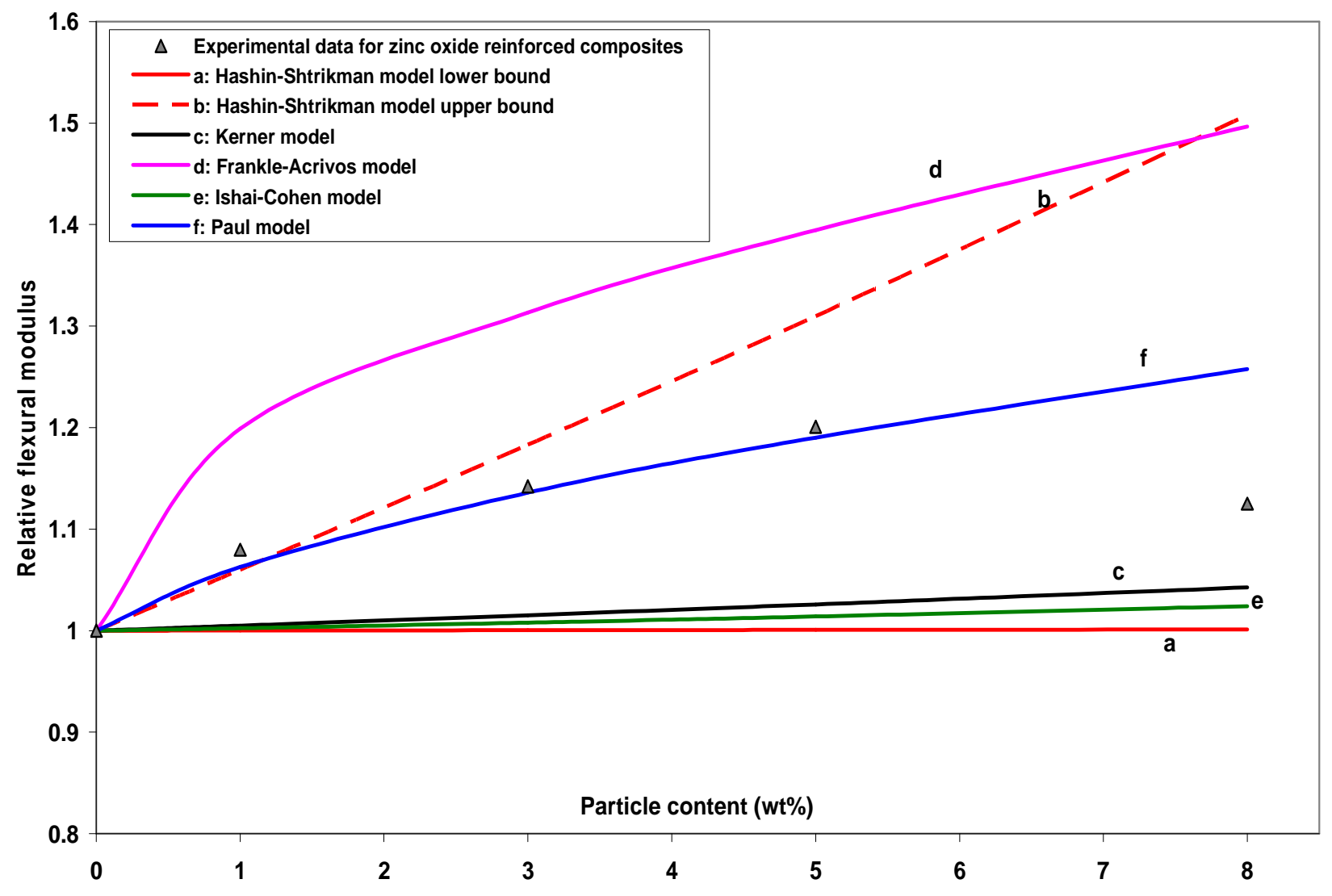

(b) 


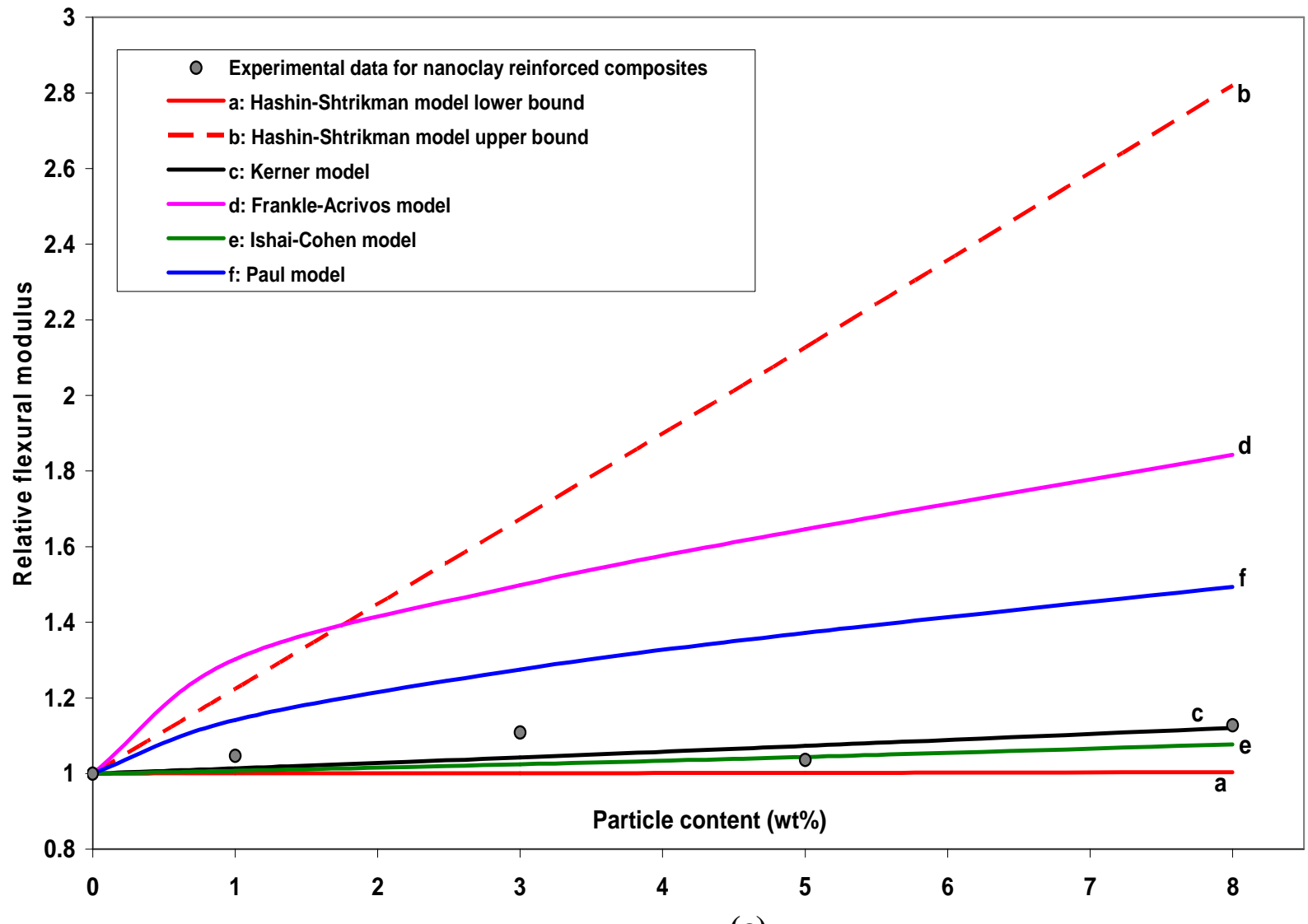

(c)

Fig. 7

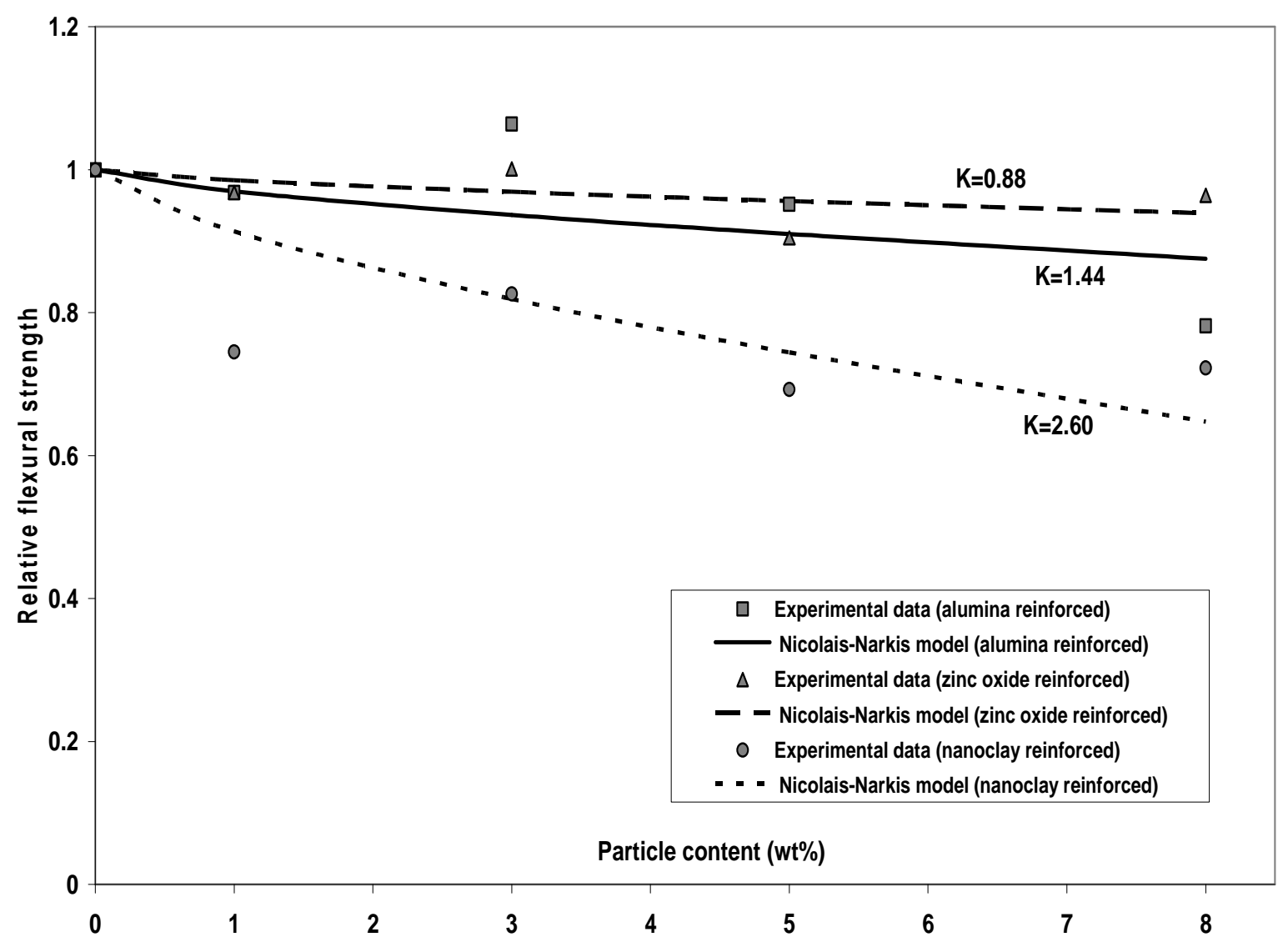

Fig. 8 
Table 1 Material properties for mathematical models used in particulate reinforced composites

\begin{tabular}{ccccc}
\hline Material & Epoxy & Alumina & Zinc oxide & Clay \\
\hline Density $\left(\mathrm{g} / \mathrm{cm}^{3}\right)$ & 1.20 & 4.0 & 5.6 & 1.98 \\
Ref. & {$[14]$} & {$[15]$} & {$[16]$} & {$[17]$} \\
$\quad$ & & & & \\
$\quad$ Young's modulus E (GPa) & $2.73^{1}$ & 375 & 140 & 178 \\
$\quad$ Ref. & & {$[15]$} & {$[18]$} & {$[19]$} \\
$\quad$ & & & \\
$\quad$ Poisson's ratio $v$ & 0.42 & 0.21 & 0.36 & 0.20 \\
$\quad$ Ref. & {$[20]$} & {$[15]$} & {$[21]$} & {$[19]$} \\
$\quad$ & & & & \\
$\quad{ }^{2}$ Shear modulus G (GPa) & 0.96 & 154.96 & 51.47 & 74.17 \\
${ }^{2}$ Bulk modulus K (GPa) & 5.69 & 215.52 & 166.67 & 98.89 \\
\hline
\end{tabular}

${ }^{1}$ Our experimental data from flexural tests.

${ }^{2}$ The values of $G$ and $K$ are calculated from $\boldsymbol{G}=\frac{\boldsymbol{E}}{2(1+v)}$ and $\boldsymbol{K}=\frac{\boldsymbol{E}}{3(1-2 v)}$.

Table 2 Flexural and impact properties of epoxy micro/nanoparticulate composites

\begin{tabular}{|c|c|c|c|c|c|c|c|c|c|}
\hline $\begin{array}{c}\text { Material } \\
\text { type }\end{array}$ & $\begin{array}{c}\text { Particle } \\
\text { content } \\
(\mathrm{wt} \%)\end{array}$ & $\begin{array}{c}\text { Flexural } \\
\text { modulus } \\
(\mathrm{GPa})\end{array}$ & $\mathrm{SD}^{*}$ & $\begin{array}{c}\text { Flexural } \\
\text { strength } \\
(\mathrm{MPa})\end{array}$ & SD & $\begin{array}{c}\text { Flexural } \\
\text { strain at } \\
\text { break }(\%)\end{array}$ & SD & $\begin{array}{c}\text { Impact } \\
\text { strength } \\
(\mathrm{J} / \mathrm{m})\end{array}$ & SD \\
\hline Neat epoxy & 0 & 2.73 & 0.208 & 104.6 & 10.14 & $\mathrm{~N} / \mathrm{A}^{\dagger}$ & N/A & 37.0 & 0.69 \\
\hline \multirow{4}{*}{ Epoxy/alumina composites } & 1 & 3.02 & 0.144 & 101.3 & 12.85 & 3.8 & 0.9 & 21.4 & 2.49 \\
\hline & 3 & 3.11 & 0.097 & 111.3 & 5.98 & 5.1 & 1.2 & 21.3 & 0.53 \\
\hline & 5 & 3.34 & 0.105 & 99.6 & 17.88 & 3.7 & 1.0 & 21.1 & 0.41 \\
\hline & 8 & 3.46 & 0.144 & 81.8 & 11.28 & 2.7 & 0.5 & 21.5 & 0.47 \\
\hline \multirow{4}{*}{ Epoxy/zinc oxide composites } & 1 & 2.94 & 0.049 & 101.3 & 6.61 & 3.9 & 0.6 & 21.8 & 2.49 \\
\hline & 3 & 3.11 & 0.063 & 104.8 & 13.95 & 4.3 & 0.9 & 20.2 & 0.90 \\
\hline & 5 & 3.27 & 0.070 & 94.6 & 4.57 & 3.2 & 0.2 & 20.8 & 0.82 \\
\hline & 8 & 3.07 & 0.175 & 100.9 & 6.63 & 3.9 & 0.5 & 20.8 & 0.47 \\
\hline \multirow{4}{*}{ Epoxy/nanoclay composites } & 1 & 2.85 & 0.187 & 78.0 & 5.61 & 3.1 & 0.2 & 21.5 & 3.47 \\
\hline & 3 & 3.02 & 0.107 & 86.5 & 6.01 & 3.2 & 0.30 & 19.9 & 0.53 \\
\hline & 5 & 2.82 & 0.100 & 72.5 & 3.29 & 2.9 & 0.19 & 20.0 & 0.69 \\
\hline & 8 & 3.07 & 0.242 & 75.6 & 4.53 & 2.8 & 0.21 & 20.1 & 0.53 \\
\hline
\end{tabular}

$* S D=$ standard deviation

${ }^{\dagger}$ Flexural strength was reached at 5\% flexural strain prior to the sample breaking according to ASTM D790. 